\title{
Malagueños cautivos en el Norte de Africa (siglo XVIII)
}

\author{
María Dolores Torreblanca Roldán \\ Lniversidad de Málaga
}

\section{INTRODUCCION}

El problema de la cautividad se plantea desde el mismo momento en que surgen conflictos bélicos entre dos bandos, ya sea por motivos económicos, disputa por la posesión de tierras y sus riquezas; políticos, surgimiento y oposición de nacionalismos: o religiosos, enfrentamiento entre creencias distintas.

Dentro de todas estas motivaciones podría encuadrarse la larga batalla secular emprendida entre España y los países musulmanes del Norte de Africa.

Tras la ocupación musulmana de la mayor parte de la Península en su afán de ampliar los territorios de Alá, la guerra santa, los Reyes Católicos culminan su Reconquista, emprendida por sus predecesores y expulsan definitivamente a los musulmanes a la orilla africana del Mediterráneo. Sin embargo, la lucha continúa aunque esta vez, debido a las circunstancias, varía su marco físico trasladándose la acción al ámbito del Mediterráneo.

El escenario de las batallas se amplía. Ya no sólo se lucha en tierras del Reino de Granada sino también en el mar y en tierras africanas donde ahora son los españoles los que intentan asentarse en Ceuta, Melilla, Orán, etc. 
Y también cambia la forma de los enfrentamientos. Los asaltos, incursiones y razzias, practicadas anteriormente por ambos sectores, se hacen ahora más frecuentes y surge así la temible figura del corsario.

Las presas más codiciadas de estos corsarios van a ser los habitantes de la costa mediterránea europea puesto que su captura suponía una doble forma de diezmar al enemigo: reducirlos en número y atentar contra su moral, ante el ataque sorpresa continuado. Además, obtenían un suculento botín con el rescate que se pagaría por estos cautivos cristianos apresados y por la captura de sus bienes.

Aunque, efectivamente, este tipo de apresamientos era efectuado por uno y otro lado, nuestro estudio se centra, preferentemente, en los prisioneros cristianos conducidos, contra su voluntad, a tierra mahometana. Y así nos encontramos con una población hispana costera asustada que vigila constantemente el mar para intentar constatar que, como aún hoỵ decimos coloquialmente, "no hay moros en la costa".

El objetivo que pretendemos con nuestro trabajo es relatar la historia de estos individuos cautivos que un día vieron totalmente alterada su vida, su quehacer cotidiano, su espacio físico, por unos años o para siempre añadiendo a la presencia de España en el Norte de Africa un mati\% sumamente doloroso.

Nuestro propósito es, precisamente, deseuredar y sacar a la luz esas historias particulares que engrosan, desde el anonimato del pueblo, los grandes acontecimientos de la época. Y para ello, hemos seleccionado, porque no es posible abarcar toda la documentación existente. al colectivo de cautivos procedentes de Málaga que padecieron tales sinsabores durante la primera mitad del siglo XVIII.

Esta documentación procede, básicamente, del archivo del Cabildo Catredalicio de Málaga aunque también hemos manejado documentos procedentes de otros archivos malagueños como son el Archivo Municipal, el Archivo de Protocolos y el de Díaz de Escovar.

\section{IA CAUTIVIDAD MAS ALLA DE LA PENIN8ULA}

Tras la expulsión de los árabes del Reino de Granada, los enfrentamientos entre cristianos y musulmanes se siguieron sucediendo pero las fronteras se habían ampliado hasta el territorio africano donde pequeños estados practicaban el corso como principal actividad económica. 
La proximidad de las costas africanas permitía a las naves enemigas musulmanas continuar atacando nuestras embarcaciones en alta mar e. incluso, desembarcar y adentrarse hasta las comarcas del interior de Andalucía, Murcia, Valencia y Cataluña sembrando el pánico entre sus pacíficos habitantes.

Los musulmanes volvían, por tanto, a la Península como corsarios en busca de un atractivo botín y todos aquellos cristianos que encontraban a su paso eran apresados a la fuerza a ciudades como Argel y Trípoli en espera de su rescate.

En el Mediterráneo más que de piratas se habla de corsos. Es preciso, por tanto, su distinción, ya sea desde un punto de vista geográfico, jurídico o económico.

El ámbito geográfico de los corsarios se encuentra ligado a las aguas del Mediterráneo mientras que los piratas operan en el ámbito atlántico, principalmente ingleses, holandeses y franceses. Los corsos han surgido y se han desarrollado en el Mediterráneo y es este su campo de acción aunque, a veces, lo sobrepasen ya que, en caso de sentirse perseguidos por las armadas cristianas, atravesaban el Estrecho y navegaban por las costas de Portugal, del Cantábrico y de las islas Canarias y llegaban, incluso, hasta Islandia, Terranova y el Báltico, logrando burlar a sus seguidores.

Jurídicamente, a diferencia de la piratería, el corsario llevaba a cabo una guerra lícita, consentida por las ciudades o el Estado del que dependían. Este permiso se presentaba bajo distintas formas: patente de corso, salvoconductos, misiones u órdenes concretas.

Pero la diferencia más clara entre corso y piratería estriba en la actividad económica que la guerra del corso estimula, mientras que la piratería se quedaba, simplemente, en una acción de bandidaje.

Comercio y corso aparecen íntimamente unidos y a ellos se debería la prosperidad económica de los estados musulmanes del norte de Africa. También, por supuesto, se verían beneficiados otros sectores económicos parejos, con lo cual la productividad de tal actividad, al margen o no del Estado, resultaba beneficiosa para una gran mayoría que, evidentemente, procuraba participar activamente.

Durante el siglo XVI se hizo extensiva la palabra piratería para designar a las actividades fraudulentas o de bandidaje llevadas a cabo por ingleses, holandeses o franceses en el Atlántico, mientras que el término 
de corsarios designaba específicamente a los que operaban en aguas del Mediterráneo.

Será en el siglo XVII, y más concretamente tras la toma de Marmora por los españoles en 1614, cuando la designación de pirata se aplique indistintamente en uno y otro lado del Estrecho de Gibraltar como consecuencia de la degeneración del corso en una guerra ilícita.

Probablemente, fueron los corsarios berberiscos los más organizados y temidos. Estos, partiendo de Berbería (Africa Septentrional) dominaron prácticamente todo el Mediterráneo Occidental. Argel y Túnez se convirtieron, por tanto, en grandes plazas de corso y comercio.

Por lo general, las naves que tropezaban con los corsarios no tenían salvación: la carga se convertía en botín de guerra, los pasajeros y la tripulación eran hechos prisioneros. En el mejor de los casos, estos recuperaban, con relativa prontitud, la libertad mediante el pago de un rescate, hasta tal punto que en Estambul y en las grandes ciudades del Imperio existían verdaderos encargados de negocios ocupados del rescate de los cristianos.

Antes de continuar se hace preciso esclarecer la distinción fundamental entre esclavitud y cautiverio. Tanto esclavitud como cautiverio indican la falta de libertad de la persona que está en poder de un enemigo. Pero mientras el esclavo se convertía además en una propiedad de su amo sin posibilidades de ser libertado, el cautivo perdía su libertad de hecho pero no de derecho, con lo cual, jurídicamente, no se convertía en esclavo (1).

El cautivo 'se reservaba para el canje por algún hermano de raza y religión o para el cobro de un suculento rescate, lo que llegó a convertirse en un floreciente negocio que sería hábilmente explotado por los musulmanes durante la Edad Moderna.

\section{AMBITO Y CIRCUNSTANCIAS DE LAS CAPTURAS}

El mayor contingente de cautivos españoles eran sorprendidos en las costas que rodean a la Península, bien cuando se dedicaban a la pesca como es el caso de Francisco Madueño, natural de Málaga, de 20 años de edad y uno y medio de cautiverio, o como Bernabé Díaz, de 60 años de edad y 6 meses de cautiverio, apresado cuando se dedicaba a las tareas agrícolas (2).

Ante la escasa eficacia de sus defensas costeras, la población malagueña se encontraba atemorizada y así lo manifestaba ante el Cabildo Municipal: 
... siendo, señor, un dolor los muchos relatos que hay ocasionados de los moros que saltan en tierra, en las cercanias de estas playas llevándose hombres, mujeres y niños de las haciendas en que estan... (3).

A su vez, en las costas de Berbería, igualmente, eran apresados españoles que se dedicaban al corso.

También la navegación en alta mar resultaba bastante peligrosa. Las diversas líneas comerciales marítimas que surcaban el Mediterráneo y las que unían la Península con las islas Canarias o América ofrecían escasas garantías de supervivencia ante un ataque enemigo: Antonio Mateos, natural de Málaga, de 60 años de edad y 6 meses de cautiverio, fue apresado como pasajero de un barco de vela (4).

En el transcurso de estas travesías eran cautivadas familias enteras como fue el caso de doña Juana Fernández Castillo, apresada junto a su marido y su hijo entre Ceuta y Gibraltar .

También el mal tiempo podía arrastrar a estos infortunados viajeros hasta las costas infieles:

Doña Beatriz Quintero, vecina de esta ciudad, mujer legítima de José Agustín Pardo, cautivo, ante mí pareció y dijo que como consta de esta certificación que presento y juro, el dicho mi marido consta de soldado artillero de la Companía de artilleros con sueldo, que es Capitán D. Chenedeo O'Brien y como tal fue nombrado para la escolta con otros artilleros para la saetia de bastimentos y presidiarios que en el mes de enero pasado de este año salió de esta ciudad para Melilla y es asi que habiendo salido de este puerto padecieron tormenta y corriendo el mal temporal dieron al través en tierra de moros que fueron aprehendidos... (6).

Otra fuente de captura de cristianos la constituían nuesiras fortalezas africanas, sobre todo, los frecuentes enfrentamientos entre las guarniciones de Ceuta y Orán con las tropas musulmanas que facilitaban el apresamiento de soldados: Matco Candela, de 17 años de edad, era soldado del regimicnto de Orán y fue cautivado en una escaramuza (7). 
Con la caída de Orán, en 1708, toda la tropa perdió la libertad $Y$, con ella, asimismo, la población civil. En total, unos cinco mil españoles, aproximadamente.

\section{SITUACION DE LOS CAUTIVOS CRIBTIANOS}

La venta de los cautivos era uno de los negocios más saneados de que disponía el Estado berberisco. Ademas del dinero que percibía por razón de los suyos propios, obtenía también el $10 \%$ de la venta de los cautivos pertenecientes a personas particulares, aparte también de otros derechos que llamaban de puertas y de salida (que se pagaban para poder abandonar la ciudad).

Nada más llegar a Argel, los nuevos cautivos cristianos eran llevados inmediatamente a la casa del dey o gobernador donde los cónsules extranjeros reconocían a sus compatriotas.

Posteriormente, el dey elegía 1 de cada 8 cautivos, prefiriendo a los más calificados, y los enviaba a los baños del deylik. Los baños eran grandes casas con un patio central rodeado de un soportal. Por medio de tabiques se dividían en habitaciones en las cuales dormían de 15 a 20 personas (8).

Los demás eran vendidos como esclavos en el batistan o mercado de esclavos de la forma que ya conocemos: los delels o pregoneros voceaban los méritos del esclavo y el dinero que se daba por él. Cuando nadie ofrecía más, el escribano destinado a levantar acta de las ventas escribía el precio del mejor postor. Tras esta primera venta se hacía una segunda en presencia del dey. Allí el esclavo era entregado al que ofreciera la mayor cantidad de dinero.

En Argel se distinguían, por lo general, varios tipos de cautivos: los mas favorecidos eran los del deylik o del Estado: algunos eran tomados por el dey para su servicio personal, como pajes. Solían ser bien tratados y recibían numerosos regalos y atenciones de los cortesanos del rey. Otros se destinaban a los cuarteles turcos para encargarse de la limpieza y cuidado de la milicia, amontonados con los turcos, su moral corría aquí sumo peligro. Los demás se destinaban a los baños.

A muchos de ellos los hacía embarcar el dey en las naves corsarias para que recibieran la parte correspondiente a su habilidad. De esta retribución percibía el dey los dos tercios y le dejaba al cautivo el tercio res- 
tante. También los ocupaba con frecuencia el dey en la construcción de las naves corsarias.

Por las noches. a todos los cautivos los encerraban en los baños. Por la mañana les abrían las puertas y los que querían salir a trabajar por su cuenta podían hacerlo, pagando un pequeño derecho al guardián o bachi, con la obligación de volver al baño todas las noches. Los que no sabían oficios se ocupaban en los trabajos comunes de las obras públicas del Cobierno.

Los cautivos de los particulares se dividían en dos grupos:

a) aquellos que cran comprados por sus señores para el cuidado de sus casas, fincas, jardines o casas de campo. Su suerte dependía, por tanto, del caracter de sus señores.

b) otros eran comprados por tagarines, moros expulsados de España, que comerciaban con los cautivos como pudieran hacerlo con cualquier otro objeto.

Nuestro escritor Cervantes, tras ser cautivado en Argel nos explica los sufrimientos a los que podían verse sometidos los cautivos cristianos:

... Y aunque la hambre y desnudez pudiera fatigarnos a veces, y aun casi siempre, ninguna cosa nos faligaba tanto como oír y ver a cada paso las jamás vistas ni oidas crueldades que mi amo usaba con los cristianos. Cada día ahorcaba el suyo, empalaba a éste, desorrjaba a aquél; y esı, por lan poca ocasión, y Ian sin ella, que los turcos conocian que lo hacía no más de por hacerlo... (9).

Pero, por lo general, eran más respetados que los cristianos libres porque cualquier daño lísico ocasionado al cautivo hacía disminuir el valor de su rescate. Incluso, muchas veces, si el castigo efectuado al cautivo era muy severo, sus dueños intentaban ocualtarlo ya que podían perderlos por decreto de la Justicia.

La ración de comida diaria se reducía a tres pequeños panes; y para dormir, les daban un pequeño colchón y una manta de lana (10).

Físicamente. los cautivos se distinguían por sus largas harbas que se dejaban crecer todo el timpo de su cautiverio. Por su parte, aque- 
Ilos que ganaban ocupaciones y preferían quedarse en Argel usaban bigote bien poblado.

Las cautivas pertenecientes al deylik estaban en la casa del chabeke beledo, corregidor de la ciudad. hasta que eran rescatadas. Las demás, las vendian a diferentes personas, a cuya brutalidad quedaban expuestas porque, aunque se podían quejar al dey, este, cuando más, se contentaba con recriminar a sus dueños, y es de suponer, que pasarían a formar parte del haréı de sus amos.

Estas eran especialmente descadas por los turcos. El turco, elemento dominador en Argel, no podía casarse con mujeres de raza Iurca porque no las había en Argel, ni tampoco con las moras, elemento indígena, ya que por ser considerados los de esta raza gente de inferior calidad. los hijos procedentes de semejantes matrimonios eran tenidos por moros. En cambio, los hijos nacidos de turcos y cristianas renegadas eran reconocidos como turcos.

\section{LA REDENCION DE CAUTIVOS WN BL BIGLO XVIII}

Durante el Antiguo Régimen la redención de cautivos va a quedar vinculada, casi exclusivamente, a las dos Ordenes redentoras por antonomasia: la Orden de la Santísima Trinidad, fundada en 1201 en el convento de Arvingaña por san Juan de Mata y la Orden de Nuestra Señora de la Merced, fundada en 1218 en Barcelona por san Pedro Nolasco.

Las redenciones estaban condicionadas a la existencia de caudales, a las necesidades de los cautivos, a las relaciones políticas estatales y las condiciones más o menos favorables propiciadas por los gobernadores musulmanes a la hora de expedir los pasaportes.

El centro principal de las redenciones era Argel, puesto que los cautivos españoles eran muy numerosos y esto permitía el rebajar los precios de los mismos. En Tínez predominaban los cristianos procedentes de otros países europeos. que en sus travesías comerciales eran igualmente apresados por los corsarios, por su situación oriental.

En sus comienzos, las primeras redenciones llevadas a cabo por las Ordenes de Nuestra Señora de la Merced y de la Santísina Trinidad eran anuales. La presencia cercana de los musulmanes hacían los viajes relativamente fáciles. Pero cuando estos se alejaron y había que atravesar el mar resultó mas ventajoso reunir grandes cantidades de dinero y en una 
sola expedición rescatar a un mayor número de cautivos. Así, se realizaron cada tres años y en lugar de hacerlo cada provincia separadamente, se reunieron en una redención general.

Los medios de que disponían estas órdenes procedían. en su mayoría, de limosnas generales, llamadas así porque no estaban destinadas al rescate de alguna persona en particular.

Muy importante y numerosa era también la aportación económica de clérigos y particulares que contribuían con cantidades importantes al rescate de cautivos. Así, fueron muchos los Patronatos que se fundaron para cubrir tales necesidades. Todos ellos imponían una serie de condiciones particulares.

Generalmente, los Patronatos ofrecían sus caudales a aquellas personas que disponían de pocos recursos para negociar su libertad ya que los adinerados no solían necesitar el apoyo de este tipo de instituciones benélicas. Dentro del grupo de estos infortunados cran las mujeres y los niños los que por su edad y sexo eran elegidos preferentemente a la hora de la redención.

Las mandas de estos Patronatos eran concedidas por el Cabildo catedralicio mediante sorteo entre los Señores Capitulares celebrados en uII primer momento, el día del aniversario de la fundación del Patronato y; posteriormente, se fijó el sorteo para todos ellos el 23 de diciembre de cada año.

Antes de la elección del cautivo al que se le concedería la manda sorteada, los familiares o amigos del cautivo debían demostrar la necesidad en que se hallaba el solicitante. Para ello, la esposa y parientes del infortunado y varios testigos declaraban sobre las condiciones del apresamiento así como de la situación económica del mismo presentando la fe de bautismo como documento acreditativo:

Yo, el infraescrito escribano del Rey, Nuestro Señor, público y perpetuo en (el número de esta ciudad de Málaga, certifico y doy fe que ante la Real Justicia de ella y de mi como lal escribano público, María de Rojas, mujer que dijo ser de José Ventura Carrasco y otros consortes, se dio pedimento ofreciendo información de como a dicho su marido lo apresaron moros argelinos viniendo de la plaza de Orán para esta ciudad en el barco nombrado San Juan y las Animas, 
perteneciente a este puerto y que éste y los demás compañeros eran pobres de toda solemnidad y presentó la fe al bautismo del referido su marido (11).

Una vez demostrada la penosa situación en que se encontraba el cautivo se le otorgaba la ayuda solicitada a través de una notificación similar a la siguiente:

Nos, el Deán y Cabildo de la Santa Iglesia de Málaga, Patronos que somos de la buena memoria que en ella instituyó y fundó para redención de cautivos el Oydor D. Diego de Villanueva Zapata, por la presente asignamos nueve mil maravedies de dicho Patronato a Juan Bautista Mayneto, natural de esta ciudad, cautivo en Argel, hijo legílimo de Nicolás Vizcaya y de Jacinta de Lara, su mujer, cuya cantidad le asignamos para ayuda a su rescate en la suerte que en el Cabildo veinte $y$ tres de diciembre de setecientos veinte y ocho tocó al señor D. Jaime de Solís y Cante, Arcediano de Vélez... (12).

La manda se refrendaba durante un año o dos pero si al cabo de este tiempo el cautivo, por cualquier otro motivo, no había sido liberado del poder de los infieles, esta pasaba a otro en iguales condiciones.

También podía suceder que el cautivo muriera antes de la llegada de la redención como fue el caso, entre otros, de Salvador Callardo, cuya manda pasó automáticamente al cautivo Pedro Martín (13).

Incluso podía suceder que el cautivo renegara, con lo cual la manda quedaba sin efecto (14).

En otras ocasiones se empleaba el dinero que era pagado por los sentenciados de la Inquisición para no llevar el hábito conocido vulgarmente como "sambenito", cantidad que solía oscilar en torno a los tres mil maravedíes (15).

También se utilizaba el dinero que llegaba de América, siendo éste una de las más importantes aportaciones pecuniarias de que disponían las redenciones pero condicionadas por las dificultades que rodeaban a las Armadas de Indias, tanto climatológicas como por los piratas filibusteros 
que acechaban de una forma continua a los barcos cargados de metales preciosos.

En menor proporción, se ayudaban los cautivos de medios propios quedando en la más absoluta miseria.

La preparación de una redención necesitaba unos requisitos previos: primeramente, se pedía la oportuna licencia a su majestad por medio de su confesor. Obtenida la autorización real se procedía entonces a solicitar la licencia del Real Consejo de Castilla para su publicación. Para el día de la publicación se suplicaba al señor corregidor que mandara limpiar las calles del itinerario y que se pregonara el adorno de balcones y ventanas. A lo largo de la mañana de la publicación se tañían todas las campanas de las iglesias de la ciudad y la procesión era anunciada con clarines y timbales.

La negociación del pasaporte constituía uno de los puntos más delicados y transcendentales. El dey de Argel generalmente no planteaba ningún problema debido al interés que tenía en que se llevaran a cabo estas redenciones. Pero no siempre las condiciones eran favorables y solía haber cambios una vez que los padres redentores se encontraban en el lugar de la redención. liste era tramitado a través del padre adminis/rador de los reales hospitales de Argel, el cual intentaba garantizar un mínimo de condiciones.

Tras esta negociación era necesario solicitar la licencia del Rey y del Consejo Real de I Iacienda, autorizando la salida de España de la redención, lo mismo que la exportación de los caudales libres de derechos e impuestos. El flete del barco conllevaba trámites, a menudo, difíciles.

En tierras infieles, una vez salvados todos los obstáculos pecuniarios los cautivos rescatados volvían a sus patrias embarcados en las naves cristianas. No obstante, antes de entrar en la ciudad debían complir ciertos requisitos como el de pasar la cuarentena embarcados en el puerto como medida preventiva.

Finalizada ésta, habiéndoseles quemado toda la ropa y todo lo que trajeran, se les entregaba ropa nueva $\mathrm{Y}$, con el consentimiento de la Junta de Sanidad del puerto, se les permitía bajar a tierra.

Una vez desembarcados, la redención concluía con la procesión de los cautivos, junto a los religiosos que lo habían hecho posible, por las calles de la ciudad para admiración y compasión de sus ciudadanos: 
... El estandarte que da principio a la procesión lo lleva el redentor segundo, y las borlas, dos cautivos. Los demás van incorporados a toda la comunidad. Los niños rescatados iban en brazos o a mano de los religiosos. En el centro de la doble fila, se llevaba la efigie de nuestro Patriarca, a hombros de los cautivos, lo mismo que la imagen de Nuestra Madre, que preside la procesión... Abrían marcha dos o cuatro clarineros y uno o dos timbaleros. Ante la imagen de Nuestra Santisima Madre, caminaban cuatro chirimías tañendo sus instrumentos. El segundo estandarte lo lleva algún cautivo de distinción, como sacerdote, religioso o capitán rescatado, y las orlas, dos religiosos de la Orden. Este estandarte va delante de nuestro padre S. Pedro Nolasco. Lleva el tercero el señor padrino, acompañado de los señores que hubiere convidado, a corta distancia de Nuestra Madre, que van, como tengo dicho, presidiendo la procesión. También van delante de Nuestra Madre los redentores con algunos niños de las manos. A la Virgen siguen las mujeres redimidas y cierran la procesión los prelados de la Merced calzados (16).

Una vez recobrada la libertad, algunos hombres ingresaban, en agradecimiento, en la Orden benefactora, aunque casi todos se hacían hermanos de las Cofradías de sus Conventos. Estos hermanos salían en las procesiones $Y$, durante todo el recorrido, eran objeto de una profunda admiración por la fe con que seguían a las divinas imágenes, soportando sobre sus hombros el peso de las cruces penitenciales o arrastrando gruesas cadenas sujetas a sus tobillos.

No hemos encontrado, por el momento, documentación relativa a cual sería el destino de las mujeres, pero es de suponer, que algunas de ellas, sobre todo las mas jóvenes y sin compromisos familiares, ingresaran también en algún convento de la Orden que las habían rescatado, o solicitaran su ingreso en alguna Cofradía a través de padres, hermanos o maridos.

MALAGUEÑOS REBCATADOS GN LA LA MITAD DEL SIGLO XVIII

En el siglo XVIII, una de las redenciones de las que se conserva mejor documentación es la de 1723 . Esta redención tuvo una gran 
importancia para la ciudad andaluza. Fueron rescatados treinta y siete malagueños, de los que podemos señalar sus características principales. Todos eran hombres, entre 15 y 65 años. Generalmente. llevaban poco tiempo de cautiverio, aunque algunos sobrepasaron los 10 años 0 , incluso, 29 años como es el caso de Pablo Antonio, de 37 años, capturado en su travesía a Italia. Costó su rescate 100 pesos (17).

De la redención de 1724, ocho de los rescatados eran malagueños, entre 23 y 60 años y muchos años de cautiverio como Bartolomé Rosa, de 60 años de edad y 26 de cautiverio, apresado junto a Cénova. cuyo rescate costó 62 pesos (18).

En la redención de 1725 sólo se encontraban dos malagueños de entre los rescatados. Esios eran: Francisco Alonso, de 40 años de edad y 18 de cautiverio, apresado en Ocán; y Juan Granados, de j0 años y 12 de cautiverio. Fue apresado pasando a Melilla y costó su rescate 230 pesos (19).

Los trinitarios calzados de Jerez de la Frontera rescataron en la redención efectuada durante el mes de diciembre de 1729 y el mes de enero de 1730 a los siguientes malagueños:

- José de los Reyes, pescador, de 60 años de edad y 4 de cautiverio. Costó su rescate con los derechos de puertas 210 pesos de a diez reales de plata.

- Andrés Pablo de Saavedra, rescatado en lugar de Tomás de Dios, de 36 años y 4 de cautiverio, cuyo rescate costó con los derechos de puertas 250 pesos de a diez reales de plata.

- Francisco de Perea, patrón de una barca, de 53 años de edad y 4 de cautiverio, cuyo rescate costó con los derechos de puertas 210 pesos de a diez reales de plata $(20)$.

En la redención hecha por las provincias de Aragón y Valencia bajo la Orden de Nuestra Señora de la Merced en los meses de mayo y junio de 1729, en la ciudad de Túnez, se libertó a Agustín Morales, de Málaga (21).

También en 1729 la Orden de la Santísima Trinidad Calzada liberó en Argel a Juan Bautista Lara, hijo de Cipriano de Lara y de Brígida de Lara, de 34 años y de cautiverio cuyo rescate costó 295 pesos de a diez de plata (22).

Lna curiosa Memoria que publicó don Ignacio Bauer Landauer en su Biblioteca Hispanomarroquí, tomo IV, nos proporciona los nombres de cincuenta y seis malagueños redimidos del cautiverio en 1739 . 
Esta se titulaba "Memoria de los cautivos cristianos que el sagrado, real y militar Orden de Nuestra Señora de la Merced, redención de cautivos, ha rescatado del poder de los infieles en la ciudad de Argel por el mes de abril de 1739 rigiendo la Silla Apostólica Clemente XII y los destinos de España S.M. D. Felipe V" (23).

Complemento de esta Memoria son los datos relacionados con dichos cautivos entresacados por Narciso Díaz de Escovar de documentos correspondientes al Convento de la Merced, a la Hermandad Sacramental de Viñeros y a la Archicofradía del Cristo de la Sangre.

Al final de la citada Memoria aparecen las siguientes firmas de P.P. Mercedarios: Fr. José Antonio Vázquez Aldana, Fr. Juan Talamanco y Fr. Juan de San Agustín. Redentores por Castilla: y Fr. Pedro Rof-Valle, Fr. Diego Ligero y Fr. Nicolás de la Santisima Trinidad, Redentores por Andalucía. El último en firmar y dar validez a la relación de los cautivos rescatados es Fr. Alonso Talamanco, escribano real y de la redención.

\section{RELACION DE MALAGUEÑO RESCATADOS POR LA MERCED EN 1723}

NoMIBHE:

A. F. de Zamora

Alonso de Mora

Alonso (García

Andrés Mateos

Antonio de Tapia

Baltasar Torruelo

Bartolomé Crifo

Bartolomé Grillo

Beriio Estuardo

Domingo Canabat

F. José Manito

Francisco Adrián

Francisco Lóper.

Guillermo Pío

J. Gabriel Escobar
EDAD NATLRAL.

APRES. EN

CaUT. LiN TPO. CalT

$\begin{array}{lllll}45 & \text { Málaga } & \text { Pasando a Melilla } & \text { Argel } & 5 \\ 41 & \text { Málaga } & \text { Pasando a Melilla } & \text { Argel } & 1 \\ 33 & \text { Málaga } & \text { Cositas de Berbería } & \text { Argel } & 11 / 2 \\ 32 & \text { Málaga } & \text { Pasando a Melilla } & \text { Argel } & 11 / 2 \\ 64 & \text { Málaga } & \text { Costas de Málaga } & \text { Argel } & 3 \\ 50 & \text { Málaga } & \text { Pasando a Melilla } & \text { Argel } & 8 \\ 50 & \text { Málaga } & \text { Cerca de Barcelona } & \text { Argel } & 4 \\ 60 & \text { Málaga } & \text { Pasando a Cénova } & \text { Argel } & 8 \\ 30 & \text { Málaga } & \text { Pasando a Allucemas } & \text { Argel } & 8 \\ 40 & \text { Málaga } & \text { Pasando a Barcelona } & \text { Argel } & 21 / 2 \\ 43 & \text { Málaga } & \text { Pasando a Melilla } & \text { Argel } & 15 \\ 45 & \text { Málaga } & \text { Costas de Berbería } & \text { Argel } & 2 \\ 70 & \text { Málaga } & \text { Pasando a Melilla } & \text { Argel } & 7 \\ 40 & \text { Málaga } & \text { Pasando a Melilla } & \text { Argel } & 5 \\ 50 & \text { Málaga } & \text { Pasando a Melilla } & \text { Argel } & 81 / 2\end{array}$




\begin{tabular}{|c|c|c|c|c|c|}
\hline 1. Lorenzo Yaestre & 26 & Málagna & Las Canarias & Argel & 7 \\
\hline José Blaneor & 40 & Málagra & Pasando a Melilla & Argel & 15 \\
\hline Juan Alonso & 36 & Málaģa & Frente: al Peñón & Argel & 3 \\
\hline Juan B. Blanco & $6 . \overline{5}$ & Málag̣a & Costas de Málaga & Argel & 8 \\
\hline Inam B. Cuillote & 50 & Málaga & Costas de Málaga & Argel & 10 \\
\hline Juan de la Rosa & $1+$ & Múlaga & Cerca de Melilla & Argel & $1.5 \mathrm{~m}$. \\
\hline Juan de la Rosa & 60 & Yúlaga & Pasando a Cerula & Argel & $21 / 2$ \\
\hline Juan (iabricl & 38 & Málaga & Pasando a Mclilla & Argel & $6 \mathrm{III}$. \\
\hline Juan I conardo & 4.5 & Málaga & Pasando a Alhucemas & Argel & + \\
\hline Iuan Sánchez & 35 & Málagăa & Frente al Peñón & Argel & 3 \\
\hline Manuel José Sánchez & 15 & Málaga & Lina tartana & Argel & 18 \\
\hline Varcos Rodrígue\% & 50 & Yálag̨a & Cerca de Fuengirula & Argel & 18 \\
\hline Viguel Blanco & 22 & Yálaga & Pasanclo a Melilla & Argel & $6 \mathrm{ml}$ \\
\hline Nicolás de Santiago & 40 & Málagra & Pasando a Melilla & Argel & 5 \\
\hline P. M. de los Santos & 45 & Mólaga & Cabo de Gatu & Argel & 7 \\
\hline Pablo Artomio & 37 & Málugana & Passando a ltalia & Argel & 29 \\
\hline Perlon Corrales & 50 & Múlaga & Frente al Peñón & Argel & $7 \mathrm{~m}$ \\
\hline Pedro .iolaseo & 50 & Válagå & Pasando a Melilla & Argel & 7 \\
\hline Pedro Quijano & 50 & Yálaga & & Argel & $1+$ \\
\hline Salvador Antonio & 15 & Yálaga & Pasando a :lluncemas & Argel & 3 \\
\hline Sebastián Gutiérrez & 60 & Múlaga & Cast. de linengirola & Argel & 20 \\
\hline Sebastián Moreno & $2+$ & Málaga & Cast de S. leclipe & Argel & 15 \\
\hline
\end{tabular}

RELACION DE MALAGUEÑO RESCATADOS POR LA MERCED ENT 1784

\begin{tabular}{|c|c|c|c|c|c|}
\hline VOMIBRE: & BDAD & NiTURAI. & APRES. EN & CAUT. EN & TPO. C.AL \\
\hline Barioloméć Rosa & 60 & Málaga & Junto a Génovn & Argel & 26 \\
\hline P'ancisco Pérez & 51 & Málaga & Pasando a Melilla & Argel & 15 \\
\hline Juan Cela & 23 & Málaga & Cerca de Liorita & Argel & 9 \\
\hline Juan de Noguera & +1 & Málaga & Saliendo de Melilla & Argel & 1 \\
\hline Juan Vargas & 29 & Málaga & Pasando a Melilla & Argel & 8 \\
\hline Manuel Mechinel & 35 & Málaga & Pasando a Melilla & Argel & 15 \\
\hline Salvador Rodríguez & $+t$ & Málaga & Salobreña & Argel & 20 \\
\hline Tomás Cómez & +8 & Yálaga & Castillo de St. Ciruz & Argel & 17 \\
\hline
\end{tabular}


RELACION DI MALAGUET̃O RESCATADOS POR LA MERCED GN 1786

NOMIBRE EDAD NATURAL APRES. EN CAUT. EN TPO. CAUT

Francisco Alonso to Málaga S. Pelipe de Orán $\quad$ Argel 18

$\begin{array}{lllll}\text { Juan Granados } 50 \text { Málaga Pasando a Melilla } & \text { Argel }\end{array}$

\section{RBLACTON DE MALAGUEÑOO REgCATADOS POR LA MERCED EN 1739}

NOMBRE

Arronio de la Feria

Antonio Vateos

Aritonio Pantoja

Bernabé Díaz

Cristóbal Armengol

848

Crisıóbal Diaz

BDAD

NATURAI.

APIRIS LEN

TPO.

Dionisio García

Esteban Marengo

Francisco Baca

Francisco Camacho

Francisco de Acosta

Prancisco García

Francisco Gil

Francisco López

Francisco Madueño

Francisco Morales

Francisco Vogales

Prancisco Sarrate

lrancisco Vázquez

Francisco Vicente Ramíre\%

Gaspar Francisco Moreno

Jerónimo Mateos

José Martínez

José Muñoz$$
37
$$

60

38

60

20

20

37

50

$+6$

22

50

4)

35

\begin{tabular}{|c|c|c|}
\hline Málaga & Viajando a Africa & $6 \mathrm{~m}$. \\
\hline Málaga & Como pasajero de un barco & $6 \mathrm{~m}$. \\
\hline Málaga & Ein el mar & 7 \\
\hline Málaga & Costus malagneñas & 6) $\mathrm{ml}$. \\
\hline Málaga & Oráı & 3 \\
\hline Málaga & Fucugirola & $9 \mathrm{m.}$ \\
\hline Marbella & lil Estrecho de Gibralar & 7 \\
\hline Torrox & Orin & 20 \\
\hline Baca & Navegando a Ceuta & 6 \\
\hline Málaga & lin el mar & $\tilde{5}$ \\
\hline Nerja & lin el mar & 5 \\
\hline Coin & Orín & 7 \\
\hline Málaga & lin el mar & 5 \\
\hline Málaga & Orin & 0 \\
\hline Málaga & Pescando & 1 \\
\hline Málaga & Pasamdo a Ceuta & 9 \\
\hline Málaga & De liuengrirola a Málaga & + \\
\hline Marbella & Pusando a Cicuia & 0 \\
\hline Coín & & + \\
\hline Málaga & Fin el mar & 2 \\
\hline Málaga & lin cl mar & 6 \\
\hline Málaga & Pescando & $6 \mathrm{~m}$. \\
\hline Málaga & Pescando cerca de la orilla & 1 \\
\hline Ardales & Pusando a Ceuta & 6 \\
\hline
\end{tabular}




\begin{tabular}{|c|c|c|c|c|}
\hline José Salvador & 25 & Málaga & En el mar & 4 \\
\hline Iosé Valderrama & 60 & Málaga & En el mar & $6 \mathrm{~m}$. \\
\hline Juan Bautista Bruno & $6 \overline{5}$ & Torrox & Pescando en 'Torrox & 21 \\
\hline Juan de Aguilar & 43 & Málaga & Viajando a Cádiz & 7 \\
\hline Juan de Mesa & 29 & Málaga & En el mar & $?$ \\
\hline Juan García & 30 & Málaga & En tierra & 5 \\
\hline Juan Garrido & 22 & Málaga & Pasando a Ceuta & $?$ \\
\hline Juan Jacinto Carbonero & 46 & Málaga & En el mar & $6 \mathrm{~m}$. \\
\hline Juan Martín & 40 & Colmenar & & 6,5 \\
\hline Juan Martín de Amores & 25 & Marbella & En el mar & 4 \\
\hline Juan Pascual de Herrera & 30 & Málaga & Vavegando a Orán & 4 \\
\hline Juan Sotelo & 23 & Málaga & Pasando a Ceuta & 8 \\
\hline Lázaro Antonio & 32 & Estepona & En el mar & + \\
\hline Manuel Antonio Navarro & 59 & Málaga & Cerca de Melilla & 9 \\
\hline Manuel Benavides & 30 & Málaga & En el mar & 9 \\
\hline Mateo Candela & 17 & Marbella & Una escaramiza en Orán & $\bar{j}$ \\
\hline Mateo Narváez & 50 & Marbella & En tierra & 5 \\
\hline Mateo Narváez & 50 & Marbella & En tierra & $j$ \\
\hline Miguel José del Castillo & 60 & Málaga & En el mar & $1.6 \mathrm{~m}$. \\
\hline Migucl Montero & $5+$ & Málaga & En el mar & 9 \\
\hline Nicolás Armengol & +0 & Málaga & Pasajero de un barco & 2 \\
\hline Nicolás Ramos & 75 & Málaga & En el mar & $6 \mathrm{~m}$. \\
\hline Pascual ligero & 21 & Málaga & Pescando & $6 \mathrm{~m}$ \\
\hline Perlro Bonavia & 43 & Málaga & En el mar & 9 \\
\hline Pedro Prancisco Madrid & 34 & Estepona & En tierra & 3 \\
\hline Pedro González & 35 & Málaga & Viajando a Ceuta & 6 \\
\hline Pedro Ortiz & 25 & Estepona & En tierra & 5 \\
\hline Pedro Vicente de Toro & 22 & Málaga & & 9 \\
\hline Rodrigo Guerrero & 30 & Málaga & Ein el mar & $1,6 \mathrm{~m}$ \\
\hline Roque García & 44 & Marbella & En el mar & 8 \\
\hline Salvador Sarmiento & 90 & Málaga & Pescando & $6 \mathrm{~m}$. \\
\hline Vicente Juan Peláez & 25 & Málaga & En el mar & $?$ \\
\hline
\end{tabular}

En la redención realizada por la Orden de la Trinidad Calzada de la provincia de Andalucía en enero de 1751 en la ciudad de Argel fueron liberados los malagueños: 
- Miguel Antonio Ruiz, cautivo durante 20 años.

- Francisco Andrés de Aranda, huérfano y marinero del barco san Francisco Javier y Santa Rita que prestaba servicio a la plaza del Peñón. Esta embarcación. yendo cargada de agua para dicha plaza, fue apresada por dos jabeques y galeotas argelinas el 5 de agosto de 1742 .

- Diego José de Torres, apresado con el anterior.

- José Ventura Carrasco, apresado por moros argelinos pasando de la plaza de Orán para Málaga en el barco llamado San Juan y las Animas, perteneciente a este puerto.

- Antonio José Ponce, marinero, apresado en el mismo barco que el anterior.

- Francisco Antonio de Arenas. apresado pasando de la plaza de Orán a esta ciudad (24).

Andrés Francisco Díaz pagó 500 pesos escudos de plata antigua por su libertad en la ciudad de Orán en el mes de junio de 1728 regresando a Málaga en un barco de nacionalidad portuguesa cuyo patrón declaró haber recogido en Gibraltar a cuatro cautivos cristianos procedentes de un navio inglés del puerto de Orán entre los que se encontraba el citado Andrés Francisco Díaz (25).

Ln caso similar es el de José Agustín Pardo, soldado artillero de la Compañía de Artilleros con sueldo. cuyo Capitán era D. Cherecedo O'Brien. Como tal fue nombrado para ir de escolta en la saetia que de esta ciudad salió con bastimento y presidiarios para Melilla. Dicha embarcación sufrió una fuerte tormenta que le arrastró a tierra de Orán donde la tripulación fue hecha cautiva. Así escribía José Agustín a su esposa sus pesares:

... luego que salimos desnudos nos tuvieron dos dias sin comer bocado y luego nos trajeron a pie y descalzos hasta Orán donde estamos cautivos tomando una poca de masa mora o bizcocho por la mañana y hasta la noche que nos dan un poco de trigo cocido no nos dan otra cosa... (26).

El 13 de julio de 1719 José Agustín Pardo compareció ante el escribano público don Alonso de Escovar al cual le presentó una cuartilla de papel escrita en árabe que fue traducida por D. Pedro Gerónimo de 
Guevara, mallorquín, Capitán de lenguas de la plaza de Melilla, residente en esta ciudad, de la manera siguiente:

Gracias a Dios Todopoderoso, Altisimo y Magnífico, sepan todos los que vieren esta generosa cédula sustancial y manifiesta narración cuyo mando es corriente $y$ de alto aprecio y veneración de los que son manpolantes en las dependencias del mundo, tanto por tierra como por mar que hemos hecho merecer a ser portador el cristiano Joseph Pardo mediante haberse rescatado su persona de nuestro poder según la costumbre y estilo que se practica entre los moros, ajustada por su precio y así nadie tenga en él autoridad ni le ponga embarazo ni le impida que vaya donde quisiere y la paz escrita por orden de Alá dada el diligente en el camino de Dios el señor Mostafá Bez el mediado de la luna desde che medi el Axer año de mil ciento y treinta (que corresponde a nuestra cuenta en el mes de mayo de mil setecientos y diez y nueve) (27).

En 1728, Luis González, natural de Málaga, hijo legítimo de Pedro González y de Salvadora de Escámez, esclavo en Orán, se rescató por 400 pesos que le prestó Bernardo José, natural de Málaga y cautivo en Orán (28).

Alonso Hilario García fue apresado cuando se dirigía a la plaza de Alhucemas en un barco llamado Jesús Nazareno y las Animas, propiedad de Manuel de Ortega, al intentar huir en un lancha. La petición de su hermano, pues era huérfano, está fechada en 27 de julio de 1726 . Alonso Hilario consiguió escapar con otros cinco compañeros presentándose el 3 de septiembre de 1728 en la secretaría de los Sres. Deán y Cabildo para confirmar el haber recibido la manda de la que era beneficiario (29).

Tomás de Dios, hijo de Jerónimo García y de Luisa Calderón, cautivo en Orán, consiguió su libertad el día 15 de junio de 1728 pagando 400 pesos escudos de plata antigua. Así consta en la certificación dada por don José Antonio Torrijos, escribano mayor del Cabildo (30). 
Juan José de Mora, en julio de 1726, salió del Puerto de Málaga en un barco con carga de bastimentos para la plaza de las Alhucemas, el cual fue cautivado el día 16 de dicho mes a vista de dicha plaza por cuatro galeotas argelinas. Su rescate fue fijado en 500 pesos quedando obligado a llevar el dinero a Orán donde había quedado como rehén Juan Jiménez Ortiz. Se presentó ante la secretaría de los Sres. Deán y Cabildo el 7 de enero de 1729 (31).

Diego José Manuel Martín recuperó su libertad el día 12 de octubre de 1734, después de 4 años de cautiverio, gracias a la victoria obtenida por los navíos españoles sobre los argelinos.

Pero no todos corrían la misma suerte que los anteriormente citados. Así, sabemos de la muerte en cautiverio de 12 de ellos:

- Cristóbal Eugenio de los Reyes

- Diego Francisco Blanco

- Francisco Martín Román

- José de Morales

- Juan Luis Martín Garrido

- Julián José de Borja

- Mateo Martín

- Miguel Francisco Díaz

- Onofre Lombar

- Pedro de Nogales

- Salvador Gallardo

- Sebastián Conejo.

$Y$, son muchos los cautivos de los cuales no hemos hallado ninguna noticia relativa a su liberación.

Cautivos rescatados

Cautivos muertos en cautiverio

Datos faltantes

\section{Datos personales de los cautivos malagueños}

La documentación presentada al Cabildo por los familiares o amigos del infortunado solicitando ayuda económica y las relaciones de los rescatados presentadas por las Ordenes de Nuestra Señora de la Merced y 
de la Santísima Trinidad nos ofrecen datos personales de los cautivados, tales como la fecha de su nacimiento, su lugar de origen, los nombres de sus padres, las circunstancias en las que se produjo su apresamiento, el tiempo que permanecieron cautivos en tierra de infieles y el precio impuesto por sus amos para acceder a su liberación.

Incluso, nos describen las características físicas de algunos de ellos. Así sabemos que Andrés Francisco Díaz era "un hombre de buen cuerpo, color blanco rehecho, ojos pardos y pelo negro" (32). Por su parte, Tomás de Dios era "de mediano cuerpo, color trigueño, ojos pardos, ocioso de viruelas, pelo negro, señales de herida en la barba y en lo alto de la ceja izquierda" (33).

\section{Bdad}

Una vez llevada a buen término la redención, los escribanos de las Ordenes redentoras certificaban la liberación de cada cautivo. En estos documentos se detallaba la edad del cautivo en el instante de ser rescatado y el tiempo que había estado cautivo. Así, contrastando ambos datos, hemos podido deducir la edad que tenían en dos momentos tan significativos en sus vidas y fijar los años de nacimiento.

Año de nacimiento

$\begin{array}{lr}1650-1660 & 4 \\ 1660-1670 & 5 \\ 1670-1680 & 26 \\ 1680-1690 & 20 \\ 1690-1700 & 17 \\ 1700-1710 & 22 \\ 1710-1720 & 13 \\ 1720-1730 & 1 \\ \text { Datos faltantes } & 173\end{array}$

De 108 cautivos cuya fecha de nacimiento conocemos, el mayor porcentaje corresponde a los nacidos entre finales del siglo XVII y comienzos del XVIII. 
Años de edad en el momento de ser cautivados

$\begin{array}{lr}0-5 & 1 \\ 5-10 & 3 \\ 10-15 & 9 \\ 15-20 & 7 \\ 20-25 & 12 \\ 25-30 & 13 \\ 30-35 & 16 \\ 35-40 & 16 \\ 40-45 & 10 \\ 50-55 & 3 \\ 55-60 & 9 \\ 60-65 & 2 \\ +65 & 2 \\ \text { Datos faltantes } & 173\end{array}$

Según los datos que nos refleja esta tabla, el mayor número de cautivos se encontraba, cuando se produce tal circunstancia: en el grupo de edad comprendido entre los 10 y los 45 años.

Los niños cautivados son muy pocos y lo mismo ocurre con los mayores de 50 años.

Lógicamente, el grupo de edad sobre el que recae el máximo riesgo se corresponde con la población activa. Esta actividad, a menudo centrada en el mar (ya fuera por comercio o por servicio militar) les convertía en las presas más fáciles.

Años de edad en el momento de la liberación

$\begin{array}{rr}10-15 & 3 \\ 15-20 & 3 \\ 20-25 & 13 \\ 25-30 & 9 \\ 30-35 & 10 \\ 35-40 & 19 \\ 40-45 & 11\end{array}$




$\begin{array}{lr}45-50 & 16 \\ 50-55 & 3 \\ 55-60 & 11 \\ 60-65 & 4 \\ +65 & 4 \\ \text { Datos faltantes } & 175\end{array}$

Esta tabla nos sitúa la edad media del grueso de los rescatados oscilando entre los 20 y los 60 años, siendo mínimos los rescatados pertenecientes a los grupos de edad anterior o posterior.

Hay que tener en cuenta, por una parte, que los cautivados solían tener entre 10 y 45 años y, sólo algunos de ellos estuvieron más de 20 años en tan penosa situación.

Por otra aparte, en estas edades los cautivos intentarían más afanosamente conseguir la libertad, aunque fuese aprovechando cualquier oportunidad para emprender una huída incierta. Tendrían, también, más posibilidades, sobre todo, físicas, de culminarla con éxito: entre otros ejemplos, Andrés Francisco Díaz consiguió por sí mismo su libertad con 23 años de edad.

\section{Sero}

De los 281 cautivos reseñados sólo 3 son mujeres:

- Francisca Mauricia Sotelo.

- Margarita Melchora Madrigal y

- Manuela de Carvajal.

En el siglo XVIII, el apresamiento de mujeres había disminuido considerablemente, en relación con siglos precedentes, debido a que ésta embarcada con mucha menos frecuencia que el hombre con lo que se encontraba alejada de la principal fuente del cautiverio.

Cuando la mujer realizaba algún viaje era en compañía de su padre, algún familiar masculino o su marido e hijos en el caso de las mujeres casadas: doña Manuela de Carvajal fue cautivada junto a su esposo, el Capitán don Jerónimo de Lara y sus hijos, Diego de ocho años y Luis, de cinco.

\section{Procedencia geográfica}

La procedencia geográfica de los cautivados durante la $1^{\text {t }}$ mitad del siglo XVIII se ciñe a la propia ciudad de Málaga siendo pocos los 
cautivos originarios de pueblos de la provincia o. incluso, naturales de otras ciudades que aparecen denominados como malagueños.

$\begin{array}{lr}\text { Alhaurín de la Torre } & 1 \\ \text { Ardales } & 1 \\ \text { Baca } & 1 \\ \text { Benamargosa } & 2 \\ \text { Ceuta } & 1 \\ \text { Coín } & 2 \\ \text { Colmenar } & 1 \\ \text { Ecija } & 1 \\ \text { Estepona } & 3 \\ \text { Málaga } & 248 \\ \text { Marbella } & 8 \\ \text { Melilla } & 1 \\ \text { Nerja } & 1 \\ \text { Torrox } & 2 \\ \text { Datos faltantes } & 8\end{array}$

\section{Iugar de cautiverio}

Un gran número de cautivos pasaron sus años de cautiverio en Argel. En este sentido, la primacía de Argel sobre las dernás ciudades musulmanas es indudable:

$\begin{array}{lr}\text { Argel } & 159 \\ \text { Orán } & 6 \\ \text { Túnez } & 1 \\ \text { Datos faltantes } & 115\end{array}$

\section{Familias}

A través del parentesco entre varios cautivos podemos comprobar la proyección social que llegaba a alcanzar la cautividad puesto que; a veces, son muchos los miembros de una misma familia los que comparten idénticas penalidades.

- 2 hermanos: José Telmo Zen y Francisco José Casimiro Zen. hijos de Domingo Zen y de Leonor Fernández. 
- 2 hermanos: Juan Gabriel Mateos y Andrés Mateos, hijos de Andrés Mateos y de María Parrilla.

- 2 hermanos: Pedro Manuel de los Santos y Pablo Agustín de los Santos, hijos de Pablo de los Santos y de María Labiosa.

- 3 hermanos: José Calderón, Pedro Clemente Calderón y Alonso Calderón, hijos de Sebastián Calderón y de Juana Galiano.

- 3 hermanos: Juan Gabriel Conejo, Andrés Diego José Conejo y Sebastián Conejo, hijos de Sebastián Conejo y de Ana Coronado.

- Una familia completa formada por don Jerónimo de Lara, doña Manuela de Carvajal y sus hijos, Diego y Luis.

\section{Tiempo en cautiverio:}

Años en cautiverio:

$0-5$

$5-10$

$10-15$

$15-20$

$+20$

Datos faltantes
59

37

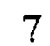

7

3

168

En esta tabla se observa claramente cómo a medida que aumentan los años de permanencia en tierras infieles disminuye el número de cautivos que aún siguen sin ser rescatados.

A lo largo de este estudio hemos intentado plantear aquellos acontecimientos que hicieron surgir la necesidad de la redención de cautivos. El análisis sistemático de toda la documentación consultada nos ha hecho conocer no sólo el marco físico e histórico en que se desarrolló la redención sino también las penalidades que sufrieron los cautivados en tierra hostil norteafricana. Por todo ello, queremos subrayar, una vez más, el carácter humanitario que permitió a muchos cautivos recuperar la libertad y volver a sus hogares. 
1. PINO. E. del.: "La esclavitud en Málaga", Jábega. n" 14, Diputación Provincial de Múlaga, 1976. pág. 41.

2. Arehivo Diaz de Escovar (A.D.E.). Caja 299. $\mathrm{n}^{\circ}$ 18: Notas curiosas de la historia de Málaga. Cautivos malagueños.

3. Archivo Municipal de Málaga (A.M.M.), Gol. Actas Capitulares, Libro n" 126, fol. 251.

4. A.D.E.. Caja 299, п" 18.

5. Ib.

6. Archivo Catedral de Málaga (A.C.M.), Legajo 219, n" 5 .

7. A.D.E., Caja 299, n" 18.

8. AI.DEA VAQLIERO y olros., Diccionario de Historia Eclesiástica: Consejo Superior de Investigaciones Cientílicas, Madrid, 1972, pág. 626.

9. CERVANTES SAAVEDRA. M. de., EI Ingenioso Hidalgo D. Quijole de la Mancha, Colección Clásicos Hispánicos Noguer, Editorial Noguer: S.A., Barcelona. 1976. pág. 427.

10. A.C.M., Legajo 219, n" 5: "Carla de un cautivo".

11. Ib.

12. Ib.

13. A.C.M., Col. Actas Capitulares, Libro n" 40, año 1712, fol. 107.

14. A.C.M., Legajo $219, n^{\circ} 5$.
15. Gll. SANJUAN, J.: "Cautivos y renegados en Berbería (1567-1582)" Baética, n" ?, Facultad de Filosofía y Letras Liniversidad de Málagu, 1984, pág. 255.

16. Garcia NAVARRO, Fr. M.: Redenciones de cautivos en Africa (1723-25), Conscjo Superior de lnvestigaciones Cientificas, Madrid, 1946, págs. 141 y 142.

17. REDER GADOW: M.: Morir en Málagr. Tesiamentos malagueños del siglo XVIII. Universidad de Málaga, 1986, págs. 181-183.

18. Ib: pág. 184.

19. Ib: pág. 184 .

20. A.C.M.. Iegajo 219, n"5, s/f.

21. Ih.

22. Ih.

23. A.D.E., Caja 299, n"18.

24. A.C.M., I egajo 219. n5. s/f.

25. Il).

26. Ib.

27. Ib.

28. Ib.

29. Il).

30. Ib.

31. Ib.

32. Ib.

33. It. 